\title{
Analysis of Deep Posterior Anal Fistulas by Magnetic Resonance Imaging: Site of Primary Abscess and Extension Patterns According to the Primary Abscess Depth
}

\author{
Yoshiro Araki ${ }^{1}$, Ryuzaburo Kagawa ${ }^{1)}$, Masahiro Tomoi ${ }^{2}$, Sadahiko Kita ${ }^{3)}$, Katsuhiko Mizuno ${ }^{3)}$, Yasumitsu Matsumura ${ }^{3)}$, \\ Ryoji Takeda" and Masaaki Awane ${ }^{3)}$ \\ 1) Department of Proctology, Rakuwakai Otowa Hospital, Kyoto, Japan \\ 2) PET-CT Examination Center, Rakuwakai Otowa Hospital, Kyoto, Japan \\ 3) Department of Surgery, Rakuwakai Otowa Hospital, Kyoto, Japan
}

\begin{abstract}
:
Objectives: The aim of this study was to use magnetic resonance imaging (MRI) to elucidate the site and depth of the primary abscesses associated with deep posterior anal fistulas and their extension patterns. Methods: We analyzed 176 consecutive patients with deep posterior anal fistulas and classified the fistulas according to whether the MRI-detected site of the primary abscess was at a superficial or a deep external anal sphincter (EAS) level. Results: The distance between the anal center and the primary abscess center was significantly shorter than the length of the EAS and radius at an angle of $45^{\circ}$. In addition, deep posterior anal fistulas with primary abscesses located at the deep EAS level penetrated the EAS significantly more laterally and made external openings at a significantly more lateral site than when the primary abscess was located at a superficial EAS level. Conclusions: Primary abscesses associated with deep posterior anal fistulas are located in the posterior intersphincteric space or in the EAS muscle itself, not in Courtney's space, as had previously been claimed.
\end{abstract}

Keywords:

anal fistula, primary abscess, external anal sphincter, MRI

J Anus Rectum Colon 2018; 2(4): 130-138

\section{Introduction}

It was long believed that the primary abscesses associated with deep posterior anal fistulas existed in the deep postanal space that was located posterior to the deep external anal sphincter (EAS) muscle, between the levator ani muscle and the superficial EAS muscle. The deep postanal space was also called Courtney's space and was first reported by Courtney. It was thought that Courtney's space might be a closed space because the superficial EAS muscle could connect to the coccyx, thereby making it difficult for an abscess in this space to drain ${ }^{1-3)}$.

Contrarily, we had advocated that the primary abscesses of deep posterior anal fistulas were located in the posterior intersphincteric space or in the EAS muscle itself, not in Courtney's space, based on magnetic resonance imaging (MRI) findings of many deep posterior anal fistulas ${ }^{4}$. The data in our previous study, however, were not sufficient to reach statistical significance. Therefore, we conducted this MRI study to elucidate more clearly our theory regarding the location of the primary abscesses of deep posterior anal fistulas and that their extension patterns can be classified according to the depth of their primary abscess. 


\section{Methods}

\section{Classification of anal fistulas}

We classified anal fistulas in this study according to Parks' classification, which includes intersphincteric, transsphincteric, suprasphincteric, and extrasphincteric fistulas ${ }^{5}$. We further classified transsphincteric fistulas according to the depth of the associated primary abscess (i.e., fistulas for which the primary abscess was located at the superficial EAS level versus those for which the primary abscess was located at the deep EAS level). It was previously reported that suprasphincteric and transsphincteric anal fistulas for which the primary abscesses were located at the deep EAS level usually had a posterior internal opening and a posterior primary abscess ${ }^{4,6}$. In contrast, intersphincteric and transsphincteric anal fistulas for which the primary abscesses were located at the superficial EAS level had their internal opening and primary abscess in either direction. Hence, transsphincteric anal fistulas with a primary abscess located at a deep or a superficial EAS level with an internal opening between 5 and 7 o'clock were considered deep posterior anal fistulas and were included in this study.

\section{Patients}

A total of 176 consecutive Japanese patients with deep posterior anal fistulas who underwent definitive anal fistula surgery at Rakuwakai Otowa Hospital between January 2009 and December 2015 were included in this study. All anal fistulas addressed in this study were due to cryptoglandular infections. Patients with Crohn's disease were excluded from the study. The included patients had already developed an anal fistula before undergoing MRI analysis and definitive anal fistula surgery. They were not in the abscess phase. Patients who had undergone definitive anal fistula surgery before referral to our hospital were considered to have a recurrent fistula. A simple drainage incision or drainage seton insertion was not considered previous anal fistula surgery. We retrospectively reviewed the patients' medical records, including their operative records and MRI findings.

\section{Magnetic resonance imaging}

All patients underwent MRI of the anus the day before surgery using Magnetom Vision Plus (1.5T) or Avanto (1.5 $\mathrm{T})$ machines during the first half of the study and Avanto (1.5T) or Skyra (3.0T) (all MRI machines were from Siemens, Munich, Germany) during the second half. These MRI machines used turbo spin echo technology. T2weighted images and fat suppressed T2-weighted images (CHESS and STIR) were obtained. Patients' hips were spread laterally, maintained by adhesive tape, and were placed in a jackknife position on an MRI table and then scanned. The images were reconstructed using axial slices (which were parallel to the line from the tip of the coccyx to the lower edge of the pubic symphysis), coronal slices (which were vertical to the former line), and sagittal slices. The MRI scans were analyzed by SDS Viewer Version 7.6 (TechMatrix, Tokyo, Japan).

\section{Analysis of anal fistulas by MRI}

We analyzed several characteristics of deep posterior anal fistulas by MRI (Figure 1a), including the direction of the internal and external openings, the primary abscess associated with the anal fistulas, and the point at which the primary abscess penetrated the EAS. These directions were expressed by "o'clock" positions, in 0.5 o'clock units. Because the direction of the external opening and the point at which the anal fistulas penetrated the EAS had right or left directions from 6 o'clock, an average calculation could offset these directions. Therefore, we also calculated their absolute value from the 6 o'clock position.

In addition, we measured the length and width of the EAS muscle, where the primary abscess might exist. The length of the EAS was the distance between the anal center and the posterior edge of the EAS. The width was measured on the line across the anal center. We viewed the anal sphincter muscle as an ellipse. The length of the EAS (L) corresponded to the semi-major axis of the ellipse. Half the width of the EAS (W/2) corresponded to the semi-minor axis of the ellipse. The distance between the anal center and the edge of the EAS at 4.5 or 7.5 o'clock nearly corresponded to the radius of the ellipse at an angle of $45^{\circ}(\mathrm{R})$, in accordance with the formula for the ellipse.

$$
\mathrm{R}=\sqrt{ } \mathrm{L}^{2} \times\left(\cos 45^{\circ}\right)^{2}+(\mathrm{W} / 2)^{2} \times\left(\sin 45^{\circ}\right)^{2}
$$$$
=\sqrt{ } 1 / 2 \times \mathrm{L}^{2}+1 / 8 \times \mathrm{W}^{2}
$$

We also measured the distance between the anal center and the primary abscess center (D). We compared D with $\mathrm{W} / 2$, $\mathrm{R}$, and $\mathrm{L}$ to determine if the primary abscess center existed within the EAS muscle (Figure 1b).

\section{Surgical procedures}

Two surgeons performed all operations, with the patients in the prone jackknife position and under general anesthesia. For transsphincteric and suprasphincteric anal fistulas, modified seton surgery was performed depending on the MRI findings $\mathrm{s}^{4,7}$. After marking the information from the aforementioned MRI analysis on the perianal skin, a circular skin incision of $25 \mathrm{~mm}$ diameter was made on the posterior anus to allow drainage of the primary abscess. Subcutaneous fat tissue was resected, exposing half of the edge of the superficial and deep EAS muscle. The primary abscess in the superficial or deep EAS was then opened and drained. A disinfected rubber band (as the cutting seton) was inserted into the internal opening through the primary abscess. Another rubber band was inserted from the external opening to the primary abscess to use as a drainage seton. The cutting se- 
a

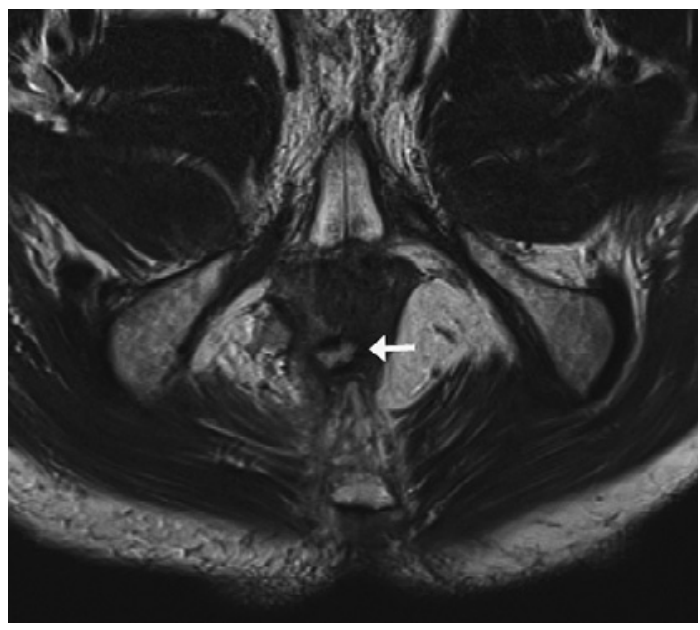

b

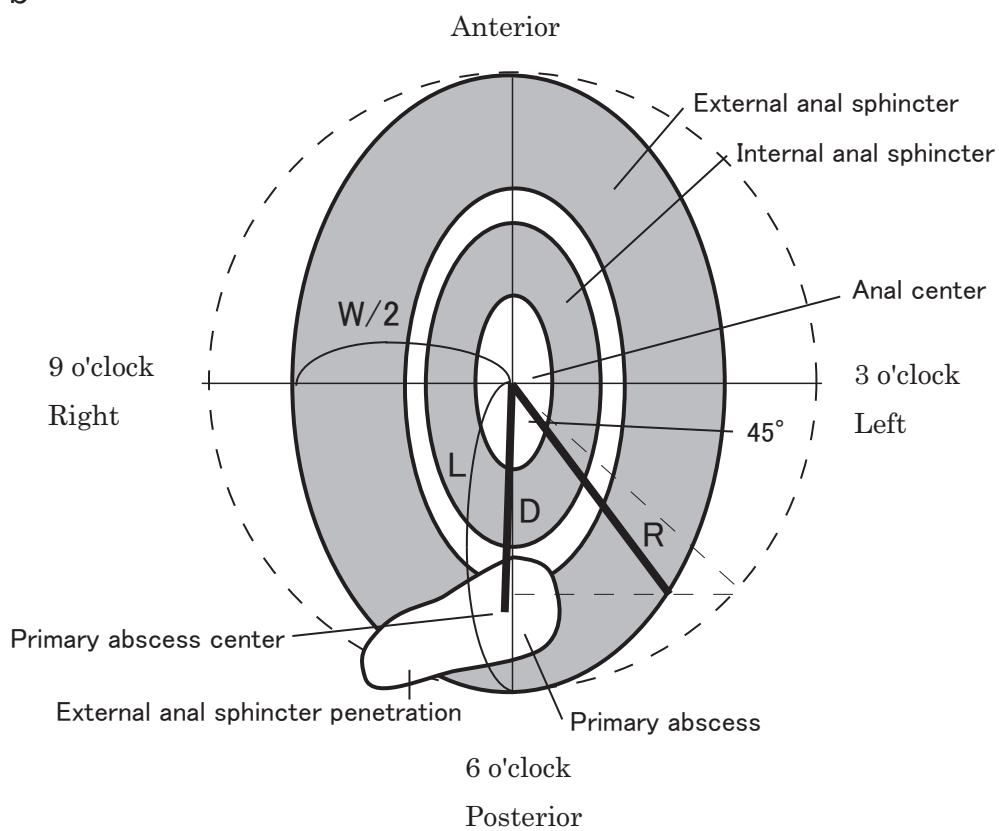

Figure 1. a: T2-weighted magnetic resonance imaging view of an axial slice. The primary abscess (arrow) associated with a transsphincteric anal fistula whose center was at a 6 o'clock position in the deep external anal sphincter (EAS) muscle penetrated the deep EAS muscle at the 7 o'clock position. b: Schema of anal sphincter muscles resembling an ellipse and a deep posterior anal fistula. $\mathrm{L}=$ the length of the EAS; W/2 = half of the width of EAS; $\mathrm{R}=$ the radius of the ellipse at an angle of $45^{\circ} ; \mathrm{D}=$ the distance between the anal center and the primary abscess center.

ton band was tightened in the outpatient unit every 2 weeks until the fistula was transected. The drainage seton band was removed 4-6 weeks after the operation. Healing of the anal fistula was confirmed when the wound was completely epithelialized, with no fluid collection apparent on MRI after the fistula was transected and the seton removed ${ }^{8}$. We named these procedures "MRI navigating seton" surgery.

\section{Statistical analysis}

Statistical analysis was performed using Student's $t$-test and the $\chi^{2}$ test. A value of $p<0.01$ was considered to indicate statistical significance.

Informed consent was obtained from all study participants. This retrospective study was approved by the institutional review board of our hospital.

\section{Results}

\section{Characteristics of patients}

The patients' characteristics are summarized in Table 1 . Among the 607 patients who underwent definitive anal fistula surgery between January 2009 and December 2015 at our hospital, 176 (165 men, 11 women; median age 47 years) had deep posterior anal fistulas. In addition, 11 of these patients had diabetes mellitus, and 50 had undergone previous definitive anal fistula surgery and were considered to have recurrent anal fistulas. Among the 176 patients with deep posterior anal fistulas, 143 had unilateral fistulas and 33 bilateral (horseshoe) fistulas. Among the 176 patients who underwent definitive anal fistula surgery at our hospital, 157 were cured, 8 were not cured, and 11 were lost to follow-up.

\section{MRI analysis of anal fistulas}

The average \pm SD direction of the internal opening of all deep posterior anal fistulas was at $5.99 \pm 0.21$ o'clock. The average \pm SD direction of the primary abscess center of anal fistulas was $6.08 \pm 0.47$ o'clock. The average \pm SD direction of EAS penetration was $6.18 \pm 1.60$ o'clock. The absolute value (average $\pm \mathrm{SD}$ ) for the direction of EAS penetration minus 6 was $1.27 \pm 1.00$ o'clock. The average \pm SD direction of the external opening was $6.18 \pm 2.73$ o'clock. The absolute value (average $\pm \mathrm{SD}$ ) for the direction of the external opening minus 6 was $2.29 \pm 1.50$ o'clock (Table 2).

The average \pm SD distance between the anal center and the posterior edge of the EAS (L) was $30.95 \pm 7.49 \mathrm{~mm}$. The average \pm SD half the width of the EAS (W/2) was $16.62 \pm 3.20 \mathrm{~mm}$. L was significantly greater than $\mathrm{W} / 2(p<$ $0.0001)$. The average $\pm \mathrm{SD}$ radius of $45^{\circ}(\mathrm{R})$ was $24.99 \pm$ $5.05 \mathrm{~mm}$. Average $\pm \mathrm{SD}$ distance between the anal center and primary abscess center (D) was $19.82 \pm 6.35 \mathrm{~mm}$. D 
Table 1. Characteristics of All Patients with Deep Posterior Anal Fistulas (2009-2015)

\begin{tabular}{lc}
\multicolumn{1}{c}{ Characteristics } & No. \\
\hline No. of patients & 176 \\
Sex (male/female) & $165 / 11$ \\
Recurrent fistula (yes/no) & $50 / 126$ \\
Depth of primary abscess & \\
Superficial EAS level & 77 \\
Deep EAS level & 99 \\
Side & \\
Unilateral & 143 \\
Bilateral (horseshoe) & 33 \\
Co-morbidities & \\
Diabetes mellitus & 11 \\
Hypertension & 17 \\
Hyperlipidemia & 9 \\
Hyperuricemia & 6 \\
Hepatic disease & 9 \\
Malignancy & 4 \\
Psychiatric disease & 8 \\
Chronic renal failure (hemodialysis) & 1 \\
Rheumatoid arthritis & 2 \\
Age (years) & $46.93 \pm 14.57$ \\
Average \pm SD & {$[35-59]$} \\
Median [IQR] & \\
Prognosis & 157 \\
Cured & 8 \\
Uncured & \\
Unknown & \\
\hline
\end{tabular}

Results are given as the number unless otherwise specified. EAS: external anal sphincter

IQR: interquartile range

was significantly greater than W/2 $(p<0.0001)$, whereas D was significantly less than $\mathrm{L}(p<0.0001)$ and $\mathrm{R}(p<$ 0.0001) (Table 2).

\section{Comparison of anal fistulas according to the depth of the primary abscess}

We divided the deep posterior anal fistulas into two groups according to the depth of the primary abscess: the superficial EAS level group $(n=77)$ and the deep EAS level group $(n=99)$. We compared the two groups concerning the aforementioned MRI findings. The sex ratio was not significantly different between the two groups. The median age was 40 years in the superficial EAS level group and 50 years in the deep EAS level group $(p=0.0002)$. Comorbidities of the two groups are shown in Table 3. In the superficial EAS level group, 12 patients (15.6\%) had recurrent anal fistulas. In contrast, in the deep EAS level group, 38 patients $(38.4 \%)$ had recurrent fistulas $(p=0.0009)$. In the superficial EAS level group, 68 patients $(88.3 \%)$ had unilateral anal fistulas, and $9(11.7 \%)$ had bilateral (horse- shoe) anal fistulas. In the deep EAS level group, 75 patients $(75.8 \%)$ had unilateral anal fistulas, and 24 (24.2\%) had bilateral (horseshoe) anal fistulas $(p=0.0343)$. In the superficial EAS level group, 71 patients were cured, and 1 was not cured. In the deep EAS level group, 86 patients were cured, and 7 were not cured $(p=0.0688)$ (Table 3$)$.

The average \pm SD direction of the internal opening was $6.02 \pm 0.27$ o'clock in the superficial EAS level group and $5.96 \pm 0.15$ o'clock in the deep EAS level group $(p=$ $0.0910)$. The average \pm SD direction of the primary abscess was $6.05 \pm 0.40$ o'clock in the superficial EAS level group and $6.10 \pm 0.52$ o'clock in the deep EAS level group ( $p=$ $0.4415)$. There was no significant difference in the average direction of the internal opening or the primary abscess between the two groups. The average \pm SD direction of EAS penetration was $5.93 \pm 1.51$ o'clock in the superficial EAS level group and $6.36 \pm 1.64$ o'clock in the deep EAS level group $(p=0.0511)$. However, the absolute value (average \pm $\mathrm{SD})$ for the direction of EAS penetration minus 6 was 1.02 \pm 1.11 o'clock in the superficial EAS level group and 1.45 \pm 0.87 o'clock in the deep EAS level group. Anal fistulas in the deep EAS level group penetrated the EAS at a significantly more lateral site than those in the superficial EAS level group ( $p=0.0017)$.

The average \pm SD direction of the external opening was $5.65 \pm 2.37$ o'clock in the superficial EAS level group and $6.6 \pm 2.94$ o'clock in the deep EAS level group ( $p=$ 0.0089 ). The absolute value (average \pm SD) for the direction of the external opening minus 6 was $1.86 \pm 1.51$ o'clock in the superficial EAS level group and $2.64 \pm 1.40$ o'clock in the deep EAS level group. The external opening of anal fistulas in the deep EAS level group were located more laterally than in the superficial EAS level group ( $p=0.0001)$ (Table 4).

The average \pm SD distance between the anal center and the posterior edge of the EAS (L) was $29.78 \pm 6.01 \mathrm{~mm}$ in the superficial EAS level group and $31.87 \pm 8.40 \mathrm{~mm}$ in the deep EAS level group $(p=0.0673)$. The average \pm SD half the width of the EAS (W/2) was $14.25 \pm 1.95 \mathrm{~mm}$ in the superficial EAS level group and $18.48 \pm 2.72 \mathrm{~mm}$ in the deep EAS level group $(p<0.0001)$. In each group, $\mathrm{L}$ was significantly greater than $\mathrm{W} / 2(p<0.0001$ and $p<0.0001$, respectively). The average $\pm \mathrm{SD}$ radius of $45^{\circ}(\mathrm{R})$ was 23.44 $\pm 3.93 \mathrm{~mm}$ in the superficial EAS level group and $26.21 \pm$ $5.50 \mathrm{~mm}$ in the deep EAS level group ( $p=0.0003)$.

The average \pm SD distance (D) between the anal center and the primary abscess center was $16.65 \pm 5.07 \mathrm{~mm}$ in the superficial EAS level group and $22.31 \pm 6.16 \mathrm{~mm}$ in the deep EAS level group $(p<0.0001)$. In each group, D was significantly greater than $\mathrm{W} / 2(p=0.0001$ and $p<0.0001$, respectively). In each group, however, D was significantly less than $\mathrm{L}$ ( $p<0.0001$ and $p<0.0001$, respectively) and $\mathrm{R}$ ( $p<0.0001$ and $p<0.0001$, respectively) (Table 4). 
Table 2. Magnetic Resonance Imaging Findings of All 176 Patients with Deep Posterior Anal Fistulas (2009-2015)

\begin{tabular}{|c|c|}
\hline Parameter & Values \\
\hline \multicolumn{2}{|l|}{ Direction of internal opening* } \\
\hline Average \pm SD & $5.99 \pm 0.21$ \\
\hline Median [IQR] & $6[6-6]$ \\
\hline \multicolumn{2}{|l|}{ Direction of primary abscess center* } \\
\hline Average $\pm \mathrm{SD}$ & $6.08 \pm 0.47$ \\
\hline Median [IQR] & $6[6.0-6.5]$ \\
\hline \multicolumn{2}{|l|}{ Direction of external anal sphincter penetration* } \\
\hline Average \pm SD & $6.18 \pm 1.60$ \\
\hline Median [IQR] & $6.5[5-7]$ \\
\hline \multicolumn{2}{|l|}{ Absolute value for direction of external anal sphincter penetration minus $6^{*}$} \\
\hline Average \pm SD & $1.27 \pm 1.00$ \\
\hline Median [IQR] & $1[0.5-2.0]$ \\
\hline \multicolumn{2}{|l|}{ Direction of external opening* } \\
\hline Average \pm SD & $6.18 \pm 2.73$ \\
\hline Median [IQR] & $6.5[4-8]$ \\
\hline \multicolumn{2}{|l|}{ Absolute value for direction of external opening minus $6^{*}$} \\
\hline Average $\pm \mathrm{SD}$ & $2.29 \pm 1.50$ \\
\hline Median [IQR] & $2[1.0-3.5]$ \\
\hline Length between anal center and the end of the external anal sphincter $(\mathrm{L})(\mathrm{mm})$ & $30.95 \pm 7.49$ \\
\hline Half of width of external anal sphincter $(\mathrm{W} / 2)(\mathrm{mm})$ & $16.62 \pm 3.20(\mathrm{p}<0.0001, \mathrm{~W} / 2$ vs L $)$ \\
\hline Radius of $45^{\circ}(\mathrm{R})(\mathrm{mm})$ & $24.99 \pm 5.05$ \\
\hline Distance between anal center and primary abscess center $(\mathrm{D})(\mathrm{mm})$ & $\begin{array}{l}19.82 \pm 6.35(\mathrm{p}<0.0001, \mathrm{D} \text { vs } \mathrm{W} / 2 ; \mathrm{p} \\
<0.0001, \mathrm{D} \text { vs } \mathrm{L} ; \mathrm{p}<0.0001, \mathrm{D} \text { vs } \mathrm{R})\end{array}$ \\
\hline
\end{tabular}

*Results are given as “o'clock” units.

Table 3. Characteristics of Patients with Deep Posterior Anal Fistulas according to the Depth of the Primary Abscess

\begin{tabular}{|c|c|c|c|}
\hline Parameter & $\begin{array}{l}\text { Superficial EAS level } \\
\qquad(\mathrm{n}=77)\end{array}$ & $\begin{array}{l}\text { Deep EAS level } \\
\quad(\mathrm{n}=99)\end{array}$ & $\mathrm{p}$ \\
\hline Sex (male/female) & $72 / 5$ & $93 / 6$ & 0.9063 \\
\hline Recurrent fistula (yes/no) & $12 / 65$ & $38 / 61$ & 0.0009 \\
\hline Side & & & 0.0343 \\
\hline Unilateral & 68 & 75 & \\
\hline Bilateral (horseshoe) & 9 & 24 & \\
\hline \multicolumn{4}{|l|}{ Co-morbidities } \\
\hline Diabetes mellitus & 4 & 7 & 0.6111 \\
\hline Hypertension & 8 & 19 & 0.1082 \\
\hline Hyperlipidemia & 3 & 6 & 0.5167 \\
\hline Hyperuricemia & 1 & 5 & 0.1736 \\
\hline Hepatic disease & 2 & 7 & 0.1809 \\
\hline Malignancy & 1 & 3 & 0.4445 \\
\hline Psychiatric disease & 4 & 4 & 0.7153 \\
\hline Chronic renal failure (hemodialysis) & 1 & 0 & 0.2579 \\
\hline Rheumatoid arthritis & 0 & 2 & 0.2097 \\
\hline Age (years) & & & 0.0002 \\
\hline Average \pm SD & $42.35 \pm 14.31$ & $50.49 \pm 13.81$ & \\
\hline Median [IQR] & 40 [32-52] & 50 [40.5-62.0] & \\
\hline \multicolumn{4}{|l|}{ Prognosis } \\
\hline Cured & 71 & 86 & 0.0688 \\
\hline Uncured & 1 & 7 & \\
\hline Unknown & 5 & 6 & \\
\hline
\end{tabular}


Table 4. MRI Findings of Deep Posterior Anal Fistulas according to the Depth of the Primary Abscess

\begin{tabular}{|c|c|c|c|}
\hline Parameters & $\begin{array}{l}\text { Superficial EAS level } \\
\qquad(\mathrm{n}=77)\end{array}$ & $\begin{array}{l}\text { Deep EAS level } \\
\quad(\mathrm{n}=99)\end{array}$ & $\mathrm{p}$ \\
\hline Direction of internal opening* & & & 0.0910 \\
\hline Average \pm SD & $6.02 \pm 0.27$ & $5.96 \pm 0.15$ & \\
\hline Median [IQR] & $6[6-6]$ & $6[6-6]$ & \\
\hline Direction of primary abscess center* & & & 0.4415 \\
\hline Average $\pm \mathrm{SD}$ & $6.05 \pm 0.40$ & $6.10 \pm 0.52$ & \\
\hline Median [IQR] & $6[6-6]$ & $6[6.0-6.5]$ & \\
\hline Direction of EAS penetration* & & & 0.0511 \\
\hline Average $\pm \mathrm{SD}$ & $5.93 \pm 1.51$ & $6.36 \pm 1.64$ & \\
\hline Median [IQR] & $6[5.5-6.5]$ & $6.75[5.0-7.5]$ & \\
\hline Absolute value for direction of EAS penetration minus $6^{*}$ & & & 0.0017 \\
\hline Average \pm SD & $1.02 \pm 1.11$ & $1.45 \pm 0.87$ & \\
\hline Median [IQR] & $0.5[0-1]$ & $1[1-2]$ & \\
\hline Direction of external opening* & & & 0.0089 \\
\hline Average \pm SD & $5.65 \pm 2.37$ & $6.6 \pm 2.94$ & \\
\hline Median [IQR] & $6[3.88-7.0]$ & 7 [4-9] & \\
\hline Absolute value for direction of external opening minus $6^{*}$ & & & 0.0001 \\
\hline Average $\pm \mathrm{SD}$ & $1.86 \pm 1.51$ & $2.64 \pm 1.40$ & \\
\hline Median [IQR] & $1.5[0.5-3.0]$ & $3[1.5-4.0]$ & \\
\hline Length between anal center and the end of EAS (L) (mm) & $29.78 \pm 6.01$ & $31.87 \pm 8.40$ & 0.0673 \\
\hline Half of width of EAS (W/2) (mm) & $\begin{array}{c}14.25 \pm 1.95(\mathrm{p}<0.0001 \\
\text { W/2 vs L })\end{array}$ & $\begin{array}{c}18.48 \pm 2.72(\mathrm{p}<0.0001 \\
\text { W/2 vs L })\end{array}$ & $<0.0001$ \\
\hline Radius of $45^{\circ}(\mathrm{R})(\mathrm{mm})$ & $23.44 \pm 3.93$ & $26.21 \pm 5.50$ & 0.0003 \\
\hline Distance between anal center and primary abscess center $(\mathrm{D})(\mathrm{mm})$ & $\begin{array}{l}16.65 \pm 5.07(p=0.0001 \\
D \text { vs } W / 2 ; p<0.0001, D \\
\text { vs } L ; p<0.0001, D \text { vs } R)\end{array}$ & $\begin{array}{c}22.31 \pm 6.16(\mathrm{p}<0.0001 \\
\mathrm{D} \text { vs } \mathrm{W} / 2 ; \mathrm{p}<0.0001, \mathrm{D} \\
\text { vs } \mathrm{L} ; \mathrm{p}<0.0001, \mathrm{D} \text { vs } \mathrm{R})\end{array}$ & $<0.0001$ \\
\hline
\end{tabular}

*Results are given in "o'clock" units.

EAS: external anal sphincter

\section{Comparison after excluding recurrent fistulas}

Next, we excluded 50 recurrent fistulas because the morphology of recurrent fistulas might be altered by the primary operations. After excluding those 50 recurrent fistulas, the anal fistulas for which the primary abscesses were in the superficial EAS level group $(n=65)$ were compared with those associated with the primary abscesses in the deep EAS level group $(n=61)$ (Table 5). The sex ratio was not significantly different between the two groups. The median patient age was 41 years in the superficial EAS level group and 48 years in the deep EAS level group $(p=0.0307)$. In the superficial EAS level group, 58 patients $(89.2 \%)$ had unilateral anal fistulas and $7(10.8 \%)$ had bilateral (horseshoe) anal fistulas. In the deep EAS level group, 48 patients (78.7\%) had unilateral anal fistulas, and $13(21.3 \%)$ had bilateral (horseshoe) anal fistulas ( $p=0.1053)$.

The average \pm SD direction of the internal opening was $6.04 \pm 0.28$ o'clock in the superficial EAS level group and $5.95 \pm 0.15$ o'clock in the deep EAS level group $(p=$ 0.0338 ). The average \pm SD direction of the primary abscess was $6.09 \pm 0.39$ o'clock in the superficial EAS level group and $6.04 \pm 0.53$ o'clock in the deep EAS level group $(p=$
0.5353). There was no significant difference in the direction of the primary abscess between the two groups.

The average \pm SD direction of EAS penetration was 6.11 \pm 1.38 o'clock in the superficial EAS level group and 6.36 \pm 1.61 o'clock in the deep EAS level group $(p=0.3119)$. However, the absolute value (average $\pm \mathrm{SD}$ ) for the direction of EAS penetration minus 6 was $0.93 \pm 1.02$ o'clock in the superficial EAS level group and $1.43 \pm 0.86$ o'clock in the deep EAS level group. Anal fistulas for which the primary abscess was in the deep EAS penetrated the EAS at a significantly more lateral site than in the superficial EAS ( $p=$ 0.0013).

The average \pm SD direction of the external opening was $5.84 \pm 2.42$ o'clock in the superficial EAS level group and $6.52 \pm 3.13$ o'clock in the deep EAS level group $(p=$ 0.1227 ). However, the absolute value (average \pm SD) for the direction of the external opening minus 6 was $1.88 \pm 1.52$ o'clock in the superficial EAS level group and $2.83 \pm 1.39$ o'clock in the deep EAS level group. The external opening of the anal fistulas in the deep EAS level group were located more laterally than in the superficial EAS level group $(p=0.0001)$.

The average \pm SD distance between the anal center and 
Table 5. Characteristics and MRI Findings of Deep Posterior Anal Fistulas according to the Depth of Primary Abscess after Excluding Recurrent Fistulas

\begin{tabular}{|c|c|c|c|}
\hline Parameters & $\begin{array}{l}\text { Superficial EAS level } \\
\qquad(\mathrm{n}=65)\end{array}$ & $\begin{array}{l}\text { Deep EAS level } \\
\quad(\mathrm{n}=61)\end{array}$ & $\mathrm{p}$ \\
\hline Sex (male/female) & $61 / 4$ & $57 / 4$ & 0.9243 \\
\hline Side & & & 0.1053 \\
\hline Unilateral & 58 & 48 & \\
\hline Bilateral (horseshoe) & 7 & 13 & \\
\hline Age (years) & & & 0.0307 \\
\hline Average $\pm \mathrm{SD}$ & $42.86 \pm 14.31$ & $48.52 \pm 14.78$ & \\
\hline Median [IQR] & $41[32-53]$ & $48[39-61]$ & \\
\hline Direction of internal opening* & & & 0.0338 \\
\hline Average \pm SD & $6.04 \pm 0.28$ & $5.95 \pm 0.15$ & \\
\hline Median [IQR] & $6[6-6]$ & $6[6-6]$ & \\
\hline Direction of primary abscess center* & & & 0.5353 \\
\hline Average \pm SD & $6.09 \pm 0.39$ & $6.04 \pm 0.53$ & \\
\hline Median [IQR] & $6[6.0-6.5]$ & $6[6.0-6.5]$ & \\
\hline Direction of EAS penetration* & & & 0.3119 \\
\hline Average \pm SD & $6.11 \pm 1.38$ & $6.36 \pm 1.61$ & \\
\hline Median [IQR] & $6[5.5-6.5]$ & $6.5[5.0-7.38]$ & \\
\hline Absolute value for direction of EAS penetration minus $6^{*}$ & & & 0.0013 \\
\hline Average \pm SD & $0.93 \pm 1.02$ & $1.43 \pm 0.86$ & \\
\hline Median [IQR] & $0.5[0.5-1.0]$ & $1[1-2]$ & \\
\hline Direction of external opening* & & & 0.1227 \\
\hline Average $\pm \mathrm{SD}$ & $5.84 \pm 2.42$ & $6.52 \pm 3.13$ & \\
\hline Median [IQR] & $6.5[4-7]$ & $7[4.0-9.5]$ & \\
\hline Absolute value for direction of external opening minus $6^{*}$ & & & 0.0001 \\
\hline Average \pm SD & $1.88 \pm 1.52$ & $2.83 \pm 1.39$ & \\
\hline Median [IQR] & $1.5[0.5-3.0]$ & $3[2-4]$ & \\
\hline Length between anal center and the end of EAS (L) (mm) & $29.98 \pm 6.28$ & $31.82 \pm 8.51$ & 0.1694 \\
\hline Half of width of EAS $(\mathrm{W} / 2)(\mathrm{mm})$ & $\begin{array}{c}14.18 \pm 1.88(\mathrm{p}<0.0001 \\
\text { W/2 vs L })\end{array}$ & $\begin{array}{c}18.72 \pm 2.79(\mathrm{p}<0.0001 \\
\text { W/2 vs L })\end{array}$ & $<0.0001$ \\
\hline Radius of $45^{\circ}(\mathrm{R})(\mathrm{mm})$ & $23.55 \pm 4.08$ & $26.26 \pm 5.66$ & 0.0025 \\
\hline Distance between anal center and primary abscess center (D) (mm) & $\begin{array}{c}17.05 \pm 5.32(p=0.0001, D \\
\text { vs } W / 2 ; p<0.0001, D \text { vs L; } \\
\text { p }<0.0001, D \text { vs } R)\end{array}$ & $\begin{array}{c}21.81 \pm 5.90(p=0.0004, D \\
\text { vs } W / 2 ; p<0.0001, D \text { vs L; } \\
\text { p }<0.0001, D \text { vs } R)\end{array}$ & $<0.0001$ \\
\hline
\end{tabular}

*Results are given in "o'clock" units.

EAS: external anal sphincter.

the posterior edge of the EAS (L) was $29.98 \pm 6.28 \mathrm{~mm}$ in the superficial EAS level group and $31.82 \pm 8.51 \mathrm{~mm}$ in the deep EAS level group $(p=0.1694)$. The average \pm SD half the width of the EAS (W/2) was $14.18 \pm 1.88 \mathrm{~mm}$ in the superficial EAS level group and $18.72 \pm 2.79 \mathrm{~mm}$ in the deep EAS level group $(p<0.0001)$. In each group, L was significantly greater than $\mathrm{W} / 2(p<0.0001$ and $p<0.0001$, respectively). The average $\pm \mathrm{SD}$ radius of $45^{\circ}(\mathrm{R})$ was 23.55 $\pm 4.08 \mathrm{~mm}$ in the superficial EAS level group and $26.26 \pm$ $5.66 \mathrm{~mm}$ in the deep EAS level group $(p=0.0025)$.

The average \pm SD distance between the anal center and the primary abscess center (D) was $17.05 \pm 5.32 \mathrm{~mm}$ in the superficial EAS level group and $21.81 \pm 5.90 \mathrm{~mm}$ in the deep EAS level group $(p<0.0001)$. In each group, D was significantly greater than $\mathrm{W} / 2(p=0.0001$ and $p=0.0004$, respectively). In each group, however, D was significantly less than $\mathrm{L}(p<0.0001$ and $p<0.0001$, respectively) and $\mathrm{R}$ $(p<0.0001$ and $p<0.0001$, respectively).

\section{Discussion}

In general, deep posterior anal fistulas develop because of infections of the posterior anal crypt, called an internal opening (primary orifice), leading to the anal gland. In turn, the infected anal gland develops posterior intersphincteric and primary abscesses, which penetrate the EAS, exit to the ischiorectal fossa, and extend unilaterally or bilaterally to external openings (secondary orifice) on the perianal skin, ${ }^{9,10}$. Deep posterior anal fistulas that extend into the ischiorectal fossa bilaterally have also been called horseshoe fistulas ${ }^{2,3111}$. 
The idea has prevailed that the primary abscess associated with deep posterior anal fistulas is present in the deep postanal space (Courtney's space), which is located posterior to the deep EAS muscle, between the levator ani and superficial EAS muscles. As Courtney's space is considered a closed space, an abscess in that location would be difficult to drain ${ }^{1-3)}$. On the basis of Courtney's theory, in earlier times, Hanley's procedure or a modified Hanley's procedure, categorized as laying open surgery, was widely applied to treat deep posterior anal fistulas ${ }^{3,11,12)}$. Seton surgery has also been applied to deep posterior anal fistulas ${ }^{4,7,12,13)}$.

In contrast, others have advocated that the primary abscess associated with deep posterior anal fistulas was located in the posterior intersphincteric space or in the EAS muscle itself, not in the deep postanal space ${ }^{4,6,14)}$. Kurihara et al. called this potential space in which such primary abscesses might be located the "posterior deep space." These previous studies, however, lacked sufficient statistical analysis. We therefore decided to conduct this study to test these hypotheses regarding the location of primary abscesses of deep posterior anal fistulas and their extension patterns.

We therefore measured the length of the EAS (L) (i.e., the distance between the anal center and the posterior edge of the EAS) and half the width of the EAS (W/2). Imagining an anal sphincter muscle to be an ellipse, we calculated the distance between the anal center and the edge of the EAS at 4.5 or 7.5 o'clock as well as the radius of the ellipse at an angle of $45^{\circ}(\mathrm{R})$. On the basis of the results of the directions of the primary abscess center and EAS penetration (Tables 2, 4, and 5), the primary abscess center might be located posterior to 4.5 or 7.5 o'clock. Therefore, to establish that the primary abscesses of deep posterior anal fistulas are located within the EAS muscle, we should show that D is significantly shorter than $\mathrm{R}$ and $\mathrm{L}$. In all posterior anal fistulas, although D was significantly greater than W/2, D was significantly less than $\mathrm{R}$ and $\mathrm{L}$ (Table 2). In the analysis regarding the depths of primary abscesses, D was significantly greater than W/2 but significantly less than $\mathrm{R}$ and $\mathrm{L}$ in both the superficial and deep EAS level groups (Table 4). After excluding the recurrent fistulas, we found that the results were same as when they were included (Table 5). Therefore, we concluded that the primary abscesses of deep posterior anal fistulas were located in the posterior intersphincteric space or in the EAS muscle itself, not in Courtney's space.

Furthermore, half the width (W/2) of superficial EAS is significantly less than the W/2 of deep EAS, although the distance between the anal center and the posterior edge of the EAS (L) was not significantly different between superficial and deep EAS (Table 4). After excluding the recurrent fistulas' data, the results were same as when they were included (Table 5). Therefore, we found that the superficial EAS was more like a narrow oval, and the deep EAS was like a wide oval.
In addition, we analyzed the direction of the internal and external openings, the site of the primary abscess associated with anal fistulas, and the point where the primary abscess of the anal fistulas penetrated the EAS. There were no significant differences in the average direction of the internal opening and the primary abscesses between the superficial EAS level group and the deep EAS level group. However, the absolute value for the direction of EAS penetration minus 6 (o'clock) in the deep EAS level group was significantly greater than that in the superficial EAS level group (Table 4). In other words, anal fistulas in the deep EAS level group penetrated the EAS at a significantly more lateral site than those in the superficial EAS level group. Furthermore, the absolute value for the direction of the external opening minus 6 (o'clock) in the deep EAS level group was significantly greater than in the superficial EAS level group (Table 4). That is, anal fistulas in the deep EAS level group had external openings at significantly more lateral sites than were found in the superficial EAS level group. After excluding recurrent fistulas, anal fistulas in the deep EAS level group also penetrated the EAS muscle and had external openings at significantly more lateral sites than were found in the superficial EAS level group.

The reason anal fistulas in the deep EAS level group penetrated the EAS at significantly more lateral sites than the superficial EAS level group is the anatomy of the EAS muscle. The superficial EAS muscle's posterior fibers run posteriorly and gather at the coccyx. In contrast, the posterior fibers of the deep EAS muscle become agglutinated to the puborectal muscle and run circularly ${ }^{15}$. Primary abscesses in the EAS muscle could run along the muscle fiber. Thus, the anatomy is in line with our results in this studythat the superficial EAS is like a narrow oval, whereas the deep EAS is like a wide oval.

We argue, however, that the posterior fibers of the superficial EAS were not attached directly to the coccyx although the fibers had gathered around it. Our previous histological study showed there was just a bundle of collagen fibers between the superficial EAS muscle and the coccyx (data not shown). Therefore, there was no closed space posterior to the deep EAS muscle, between the levator ani muscle and the superficial EAS. We therefore surmised that there could be no Courtney's space.

There are some limitations of this study. First, we viewed the anal sphincter muscle as an ellipse. In fact, the shape of the anal sphincter muscle varies according to sex and among individuals, and it may not necessarily resemble an ellipse. In addition, deep posterior anal fistulas display a variety of morphologies, which may not necessarily be compatible with those of our model.

In summary, primary abscesses of deep posterior anal fistulas are located in the posterior intersphincteric space or in the EAS muscle, not in Courtney's space. Deep posterior 
anal fistulas derived from a primary abscess found at the deep EAS level penetrated the EAS more laterally and created external openings at more lateral sites than when the primary abscess was located at the superficial EAS level.

\section{Acknowledgments}

We thank Nancy Schatken, BS, MT (ASCP), from Edanz Group for editing a draft of this manuscript.

\section{Conflicts of Interest}

There are no conflicts of interest.

\section{Source of Funding}

The authors did not obtain any grants or funding for this study.

\section{References}

1. Courtney H. The posterior subsphincteric space; its relation to posterior horseshoe fistula. Surg Gynecol Obstet. 1949 Aug; 89(2): 222-6.

2. Hamilton CH. Anorectal problems: the deep postanal space - surgical significance in horseshoe fistula and abscess. Dis Colon Rectum. 1975 Nov-Dec; 18(8): 642-5.

3. Hanley PH, Ray JE, Pennington EE, et al. Fistula-in-ano: a tenyear follow-up study of horseshoe-abscess fistula-in-ano. Dis Colon Rectum. 1976 Sep; 19(6): 507-15.

4. Kagawa R, Nomura H, Takeda R, et al. [Anatomical course of deep anal fistulous tracts as analyzed by MRI]. Nippon Daicho Komonbyo Gakkai Zasshi. 2008 Apr; 61(4): 151-60. Japanese.

5. Parks AG, Gordon PH, Hardcastle JD. A classification of fistula- in-ano. Br J Surg. 1976 Jan; 63(1): 1-12.

6. Kurihara H, Kanai T, Ishikawa T, et al. A new concept for the surgical anatomy of posterior deep complex fistulas: the posterior deep space and the septum of the ischiorectal fossa. Dis Colon Rectum. 2006 Oct; 49(10 suppl): s37-44.

7. Tokunaga Y, Sasaki H, Saito T. Clinical role of a modified seton technique for the treatment of trans-sphincteric and suprasphincteric anal fistulas. Surg Today. 2013 Mar; 43(3): 245-8.

8. Araki Y, Kagawa R, Yasui H, et al. Rules for anal fistulas with scrotal extension. J Anus Rectum Colon. 2017 Jan; 1(1): 22-8.

9. Parks AG. Pathogenesis and treatment of fistula-in-ano. Br Med J. 1961 Feb 18; 1(5224): 463-9.

10. Eisenhammer S. A new approach to the anorectal fistulous abscess based on the high intermuscular lesion. Surg Gynecol Obstet. 1958 May; 106(5): 595-9.

11. Hanley PH. Conservative surgical correction of horseshoe abscess and fistula. Dis Colon Rectum. 1965 Sep-Oct; 8(5): 364-8.

12. Held D, Khubchandani I, Sheets J, et al. Management of anorectal horseshoe abscess and fistula. Dis Colon Rectum. 1986 Dec; 29 (12): 793-7.

13. Ustynoski K, Rosen L, Stasik J, et al. Horseshoe abscess fistula: seton treatment. Dis Colon Rectum. 1990 Jul; 33(7): 602-5.

14. Zhang H, Zhou ZY, Hu B, et al. Clinical significance of 2 deep posterior perianal spaces to complex cryptoglandular fistulas. Dis Colon Rectum. 2016 Aug; 59(8): 766-74.

15. Netter FH. Atlas of human anatomy. 6th ed. Philadelphia, PA: Saunders Elsevier; c2014; p. 329-97.

Journal of the Anus, Rectum and Colon is an Open Access journal distributed under the Creative Commons Attribution-NonCommercial-NoDerivatives $4.0 \mathrm{In}$ ternational License. To view the details of this license, please visit (https://creativ ecommons.org/licenses/by-nc-nd/4.0/). 